\title{
Yoga as a Tool for promotion of Mental and Physical Health Leading to Better Performance of School Children's
}

\author{
Acharya Balkrishna ${ }^{1}$, Kuldeep Singh ${ }^{2 *}$, Vinay K. Sharma ${ }^{3}$, Swami Narsingh Chandra Dev ${ }^{3}$ and Paran Gowda ${ }^{1}$ \\ ${ }^{1}$ University of Patanjali,|Patanjali Research Institute, Haridwar, India
}

${ }^{2}$ Dental Clinic and Research Centre, Patanjali Ayurved Hospital, Haridwar, India

${ }^{3}$ Patanjali Research Institute, Haridwar, India

Submission: May 25, 2019; Published: August 02, 2019

*Corresponding author: Kuldeep Singh,Dental Clinic and Research Centre, Patanjali Ayurved Hospital, Haridwar, India

\begin{abstract}
Background: Students are exposes to different standards and options and they have a lot of pressure from their parents, society and schools to perform. It is well known that the Yoga practice can improved health and mental condition, therefore it may help to improve the mind-body awareness, self-regulation and physical fitness of students.

Aim: The qualitative observational study was nested in a randomized, controlled trial studying the effects of a Yoga program offered in place of sports classes at a school.

Methods: Student interactions were done by distributing the questionnaires after the completion of a yearlong Yoga program. A formal consent was taken by their parents before the interactions. Out of the 800 students selected for the study, 700 were involved intensively in the Yoga program and the 100 students were only participated in the physical education program.

Results and Conclusion: The results indicated that all the 700 students include were enjoyed equally the Yoga classes and reveled enhancement in their memory, mental health, positive thinking and school performance. Interestingly, the other 100 students those were not involved in the Yoga practice were showed less improvements in the same. In addition, the non-responsive male and females in non-Yoga practicing group were more as compare to those who practice Yoga. Thus, the above obtained results concludes that Yoga practices in school not only good for overall health of the students, but also helped them to improve their social status as well as preventing the negative patterns observed during the juvenile transition phase of life.
\end{abstract}

Keywords: Yoga; school performance; mental health; stress

\section{Introduction}

In modern society children are exposes to different standards and options and they have a lot of pressure from their parents, society and schools to perform. Therefore, it is important for the children and young peoples to become stress free for better performance at home and schools [1]. Stress is responsible for anxiety, insomnia, muscle pain, high blood pressure, and a weakened immune system. It has been reported that stress may also lead heart problem, depression and obesity [2-4]. In addition to the above diseases stress can also lead to dental problems such as canker sores, teeth grinding, gum diseases, TMJ disorders, burning mouth syndrome and dry mouth etc [5]. According to recent reports reduced functioning abilities due to mental problems such as anxiety, depression, and behavioral disorders have been reported in children's [6]. As per another study, the sense of expectations from young ones creates stress among them, which impacts their mental health and well-being, as well as hampers their school performance [7].

Yoga has been practiced in India since centuries and is known for physical posturing and movements includes breathing exercises, relaxation, and meditation [8] (Figure 1). The main aim of Yoga is to be unifying the self at physical, emotional, cognitive, spiritual, and social levels [9]. Though a large number of adults claimed that Yoga is beneficial to them not only for psychological well-being but also to manage the stress, still fewer studies have been published on the importance of Yoga in children [10]. Since 
decade numerous articles have been published on Yoga and its effectiveness in treating various disorders in adults such as psychological/psychiatric, depression, anxiety and insomnia [11-21].

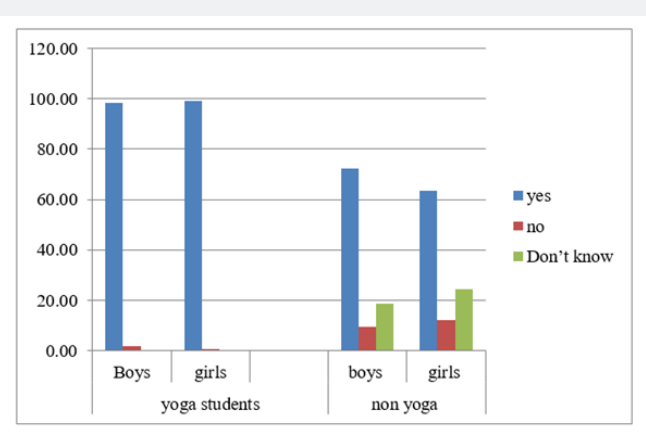

Figure 1: Comparative status of physical fitness in yoga and non-Yoga practitioners based on questionnaire.

Some studies suggested to include improved mood and reductions in stress in improvement of mental health of healthy children and adolescents [22-24]. Another study in which high school students were randomly assigned to Yoga program for 12 weeks during Physical Education (PE) showed significant pre/post improvements in resilience to stress, negative effect, anxiety, and anger control relative to control [25]. The similar group latter studies the qualitative assessment program on Yoga for high school students. In their study they conduct the qualitative interview and the study was nested in a randomized, controlled trial to observe the effects of a Yoga program instead of physical education classes at a rural public high school. In this study they observed that the children opted for Yoga program claimed for psychological benefits, stress reduction, better management of negative emotions; and optimism. In addition, most of them believed that Yoga could reduce interest in the use of drugs and alcohol and increase social cohesion with family and peers [26]. Another study suggested that the Yoga is a tool to listen to your heart and can be useful for young adults as well as children. Recently, our group also confirmed that Yoga is one of the best practices to improve the overall wellbeing and personality of children to make them capable of facing the present-day challenges and problems [27-29]. Thus, above discussion indicated that the practice of Yoga has important role in improving health and mental condition especially in case of stress and anxiety [30].

The Yoga practice in school may help to improve the mindbody awareness, self-regulation, and physical fitness. These improvements may result in the students' a good behavior, better mental state and health including their performance as well as coping with classroom stress. Therefore, in the current study we designed a randomized study to establish the relationship between practice of Yoga and its effect on health of young children.

\section{Materials and Methods}

For the current study eight hundred students were randomly selected from different schools (Government Primary \& High
Schools of Haridwar area, Uttarakhand, India) among them seven hundred students were subjected to Yoga practices whereas hundred were involved in other physical activities. The overall age of students who participated in the study was 6 to 15 years and Yoga awareness Questionnaire form was filled by each of them. The study was further categorized between male and female.

The inclusion criteria included

a. male and female students with age group between 615-year,

b. willingness to participate in the study, and

c. no hospitalization in the last 3 months.

The exclusion criteria included

a. Physical challenge with systematic disease, any history of neurological or psychiatric disturbances and

b. learning disability if any (i.e., slow learner).

\section{Result}

In the current experimental setup, we have studied the effect of Yoga on high school children. Accordingly, we have divided them into two groups i. e. Yoga practicing group and non-Yoga practicing group (physical education group) and performed the qualitative studies by distribution the questionnaires among them. (Table 1) Throughout our study we have assessed various aspects of Yoga and correlate it with the mental health, positive thinking and school performance of children. The result indicated that $98.30 \%$ male and $99.27 \%$ females in Yoga practicing group believed that Yoga helps them to feel healthy. Similarly, in nonYoga group (involved in physical education) $72.31 \%$ male and $63.64 \%$ female also felt somewhat better however $9.23 \%$ male and $12.12 \%$ female did not find any improvement. Interestingly, a small group including $18.46 \%$ male and $24.24 \%$ female could not make any response at all (Figure 2). These results suggested that Yoga practices can play an important role in improving health of school children, when included in the school curriculum. In 
case of memory improvement, we got some very interesting results as we have found $97.44 \%$ male and $98.05 \%$ female in Yoga practicing group considered that Yoga improves their memory as compare to only $38.46 \%$ male and $45.45 \%$ female in
non-Yoga practicing group. It was also observed that $94.6 \%$ male and $87.56 \%$ female in Yoga practicing group reported that Yoga releases their stress.

Table 1: Questionnaires based results from Yoga and Non-Yoga groups.

\begin{tabular}{|c|c|c|c|c|c|c|c|}
\hline \multirow{2}{*}{ Attributes } & \multirow{2}{*}{ Response } & \multicolumn{3}{|c|}{ Yoga group } & \multicolumn{3}{|c|}{ Non-Yoga group } \\
\hline & & Boys & Girls & Total & Boys & Girls & Total \\
\hline \multirow{3}{*}{ Do yoga make you feel physically more healthy/fit } & Yes & 98.3 & 99.27 & 98.82 & 72.31 & 63.64 & 69.39 \\
\hline & No & 1.7 & 0.73 & 1.18 & 9.23 & 12.12 & 10.2 \\
\hline & No response & 0 & 0 & 0 & 18.46 & 24.24 & 20.41 \\
\hline \multirow{3}{*}{ Do you think/feel that Yoga has improved your memory? } & Yes & 97.44 & 98.05 & 97.77 & 38.46 & 45.45 & 40.82 \\
\hline & No & 2.56 & 1.95 & 2.23 & 53.85 & 39.39 & 48.98 \\
\hline & No response & 0 & 0 & 0 & 7.69 & 15.15 & 10.2 \\
\hline \multirow{3}{*}{ Does yoga reduce study related stress and other types of stress? } & Yes & 94.6 & 87.56 & 90.81 & 75.38 & 63.64 & 71.43 \\
\hline & No & 5.4 & 12.44 & 9.19 & 16.92 & 18.18 & 17.35 \\
\hline & No response & 0 & 0 & 0 & 7.69 & 18.18 & 11.22 \\
\hline \multirow{3}{*}{ By doing Yoga, did your overall performance in school be good? } & Yes & 98.3 & 94.63 & 96.33 & 81.54 & 84.85 & 82.65 \\
\hline & No & 1.7 & 5.37 & 3.67 & 16.92 & 12.12 & 15.31 \\
\hline & No response & 0 & 0 & 0 & 1.54 & 3.03 & 2.04 \\
\hline \multirow{3}{*}{ Does yoga brings good thoughts to your mind? } & Yes & 99.15 & 99.27 & 99.21 & 84.62 & 84.85 & 84.69 \\
\hline & No & 0.85 & 0.73 & 0.79 & 12.31 & 6.06 & 10.2 \\
\hline & No response & 0 & 0 & 0 & 3.08 & 9.09 & 5.1 \\
\hline \multirow{3}{*}{$\begin{array}{l}\text { Do you think Yoga is helpful in your mental and physical develop- } \\
\text { ment/ improvement? }\end{array}$} & Yes & 96.31 & 100 & 98.29 & 64.71 & 76.92 & 100 \\
\hline & no & 3.69 & 0 & 1.71 & 35.29 & 23.8 & 100 \\
\hline & No response & 0 & 0 & 0 & 0 & 0 & 0 \\
\hline
\end{tabular}

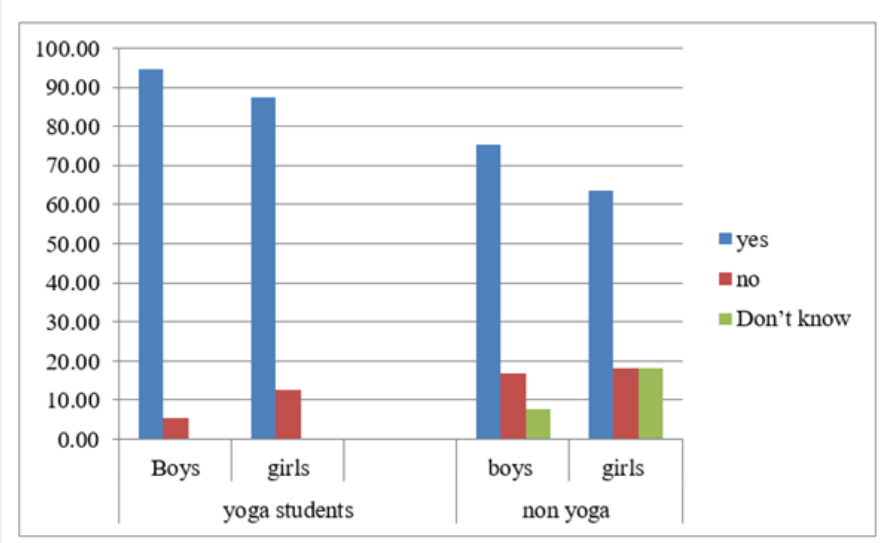

Figure 2: Comparative status of stress in yoga and non-Yoga practitioners based on questionnaire.

Similar results were obtained from $75.38 \%$ males and $63.64 \%$ females in non-Yoga practicing group (Figure 3). Regarding school performance, 98.30\% male and $94.63 \%$ female in Yoga practicing group confirmed that Yoga improves their school performance likewise $81.54 \%$ male and $84.85 \%$ female in nonYoga practicing group felt the same. Further, $99.15 \%$ male and 99.27\% female in Yoga practicing group confessed that they can think more positively then before and $64.71 \%$ male and $35.25 \%$ female in non-practicing group observed the same. Interestingly, non-responsive male and females are found more in case of nonYoga practicing group as compared to Yoga practicing group. The positive correlation between the two groups is $r=0.79$. Thus, the above results confirmed that the Yoga not only plays an important role in improving the lifestyle of the students but also have good effect on their social status. 


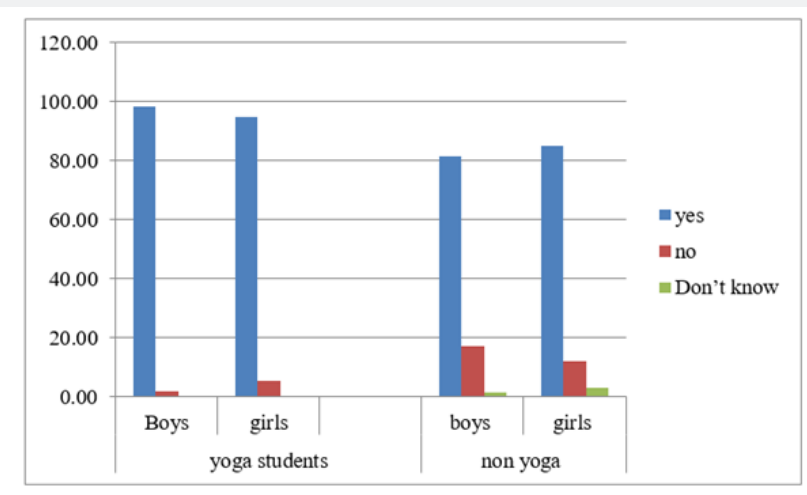

Figure 3: Comparative status of school performance in yoga and non-Yoga practitioners based on Questionnaire.

\section{Discussion}

Yoga has become the global phenomenon in recent decades due to its positive effects on various aspects of life including calmness of mind, overall health and well-being of the society. As children are more easily affected by mental and physical problems, Yoga can improve their mental health and well-being, help in developing good associations with parents and teachers, and help them to maintain the emotional, mental, and behavioral gestures [31]. In the present study we have evaluated qualitative analysis of students who were practicing Yoga for last one year at the school. We have correlated the Yoga practices with their lifestyle and our questioner was based on various aspects of Yoga practices such as

a. The practice of Yoga within the school chart,

b. Apparent benefits of Yoga

c. Their involvement in a research study.

Among the 800 subjects, 700 were practicing Yoga and 100 were involved in other physical activities. Mostly all the students confirmed that Yoga improved their lifestyle in various aspects such as improved in their healthy, reduced reactivity to stressful social situations, positive thinking and memory. Even the students who were not involved in Yoga practices have also shown their interest in Yoga to improve their mental as well as physical health. During our interaction with the students they not only informed us about the good aspects of Yoga but also gave some suggestions to improve our study design in future (such as involvement of variety of classes), and how we can improve the quality of research with the improved questionnaires to get better results. In addition, they suggested to simplify some difficult postures (asanas) and/or to train them with a Yoga trainer for regulated breathing techniques (pranayamas), hand poses (mudras), and meditation The viewpoint of the students will help us to design our future research program as some students recommended that we should not substitute the sports to Yoga in school curriculum instead we can introduce it as a separate program then it will be an added advantage for them. Though, the Yoga studies in adults have shown good effect on their mental status and reducing their stress level Sill there is a need for such studies in children.

Improvements in self-compassion have also been reported during Yoga practice suggesting that body awareness may be a mechanism of change associated with Yoga practice [32-35]. Furthermore, in current scenario unhealthy food habits is the main problem among children and some of the students have also reported that their food habits have changed during their Yoga classes. It implies that body awareness and dietary changes are integral part of Yoga practices and can prevent obesity and unhealthy food habits in children which is also supported by other studies [36-39]. In addition, students also felt that their self-esteem has improved during Yoga practices it implies that Yoga not only benefits them to choose their desired field of interest as well as help them to take decision independently.

Interestingly, we have also observed that Yoga practices help them to get rid of their bad habits by helping them to develop strong will power this is exciting results as their strong will power help them to get rid of telling a lie, taking drugs or other bad habits. Therefore, our findings highlight the importance of Yoga specially for improving the mental and physical health of the students, which can dramatically improve their aptitude to make positive decision, which not only affect their personal life but also have a good impact on our society.

\section{Conclusion}

Yoga has a positive impact on promotion of physical fitness, Mental wellbeing, memory level, school performance and reduces the stress level of school children. so, it can be concluded that school-based Yoga is helpful for overall development of children. There is a scope for research work in how to introduce Yoga as a curriculum in schools for the holistic child development and childhood sociology.

\section{References}

1. Hagen I, Nayar US (2014) Yoga for Children and Young People's Mental Health and Well-Being: Research Review and Reflections on the Mental Health Potentials of Yoga. Front Psychiatry 2: 5-35. 


\section{Journal of Yoga and Physiotherapy}

2. Chauvet-Gelinier JC, Bonin B (2017) Stress, anxiety and depression in heart disease patients: A major challenge for cardiac rehabilitation. Ann Phys Rehabil Med 60(1): 6-12.

3. Hammen C, Kim EY, Eberhart NK, Brennan PA (2009) Chronic and acute stress and the prediction of major depression in women. Depress Anxiety 26(8): 718-723.

4. Scott KA, Melhorn SJ, Sakai RR (2012) Effects of Chronic Social Stress on Obesity. Curr Obes Rep 1(1): 16-25.

5. Kuldeep Singh, Pooja Singh, Gurpreet Oberoi (2017) Effect of yoga on promotion of oral health. IJDR 2(1): 18-21.

6. Hagen I (2009) The role of new media technologies and the internet in the promotion of mental health of children. Background Document for the Thematic Conference: Promoting of Mental Health and WellBeing of Children and Young People - Making it Happen Stockholm EU/Swedish National Institute of Public Health 32-38.

7. Balkrisna A (2010) Syllabus for Yoga. Concept of Yoga Education in India. Haridwar: Divya Prakashan.

8. Woodyard C (2011) Exploring the therapeutic effects of yoga and its ability to increase quality of life. Int J Yoga. 4(2): 49-54.

9. Arndt Büssing, Andreas Michalsen, Sat Bir S Khalsa, Shirley Telles, Karen J (2012) Sherman Effects of Yoga on Mental and Physical Health: A Short Summary of Reviews. Evid Based Complement Alternat Med pp 7: 165410 .

10. Quilty MT, Goldstein R, Khalsa SBS, Saper RB (2013) Yoga in the real world: Perceptions, Motivators, Barriers, and patterns of Use. Glob Adv Health Med 2(1): 44-49.

11. Goyeche JR (1979) Yoga as therapy in psychosomatic medicine. Psychother Psychosom 31(1-4): 373-381.

12. Khalsa SB (2004) Yoga as a therapeutic intervention: a bibliometric analysis of published research studies. Indian J Physiol Pharmacol 48 269-285.

13. Sharma I, Singh P (1989) Treatment of neurotic illnesses by yogic techniques. Indian J Med Sci 43(3): 76-79.

14. Pilkington K, Kirkwood G, Rampes H, Richardson J (2005) Yoga for depression: the research evidence. J Affect Disord 89(1-3: 13-24

15. Streeter CC, Whitfield TH, Owen L (2010) Effects of yoga versus walking on mood, anxiety, and brain GABA levels: a randomized controlled MRS study. J Altern Complement Med 16(11): 1145-1152.

16. Agte VV, Chiplonkar SA (2008) Sudarshan kriya yoga for improving antioxidant status and reducing anxiety in adults. Altern Complement Ther 14(2): 96-100.

17. Kirkwood G, Rampes H, Tuffrey V, Richardson J, Pilkington K (2005) Yoga for anxiety: a systematic review of the research evidence. $\mathrm{Br}$ Sports Med 39(12): 884-891.

18. Rao MR, Raghuram N, Nagendra HR (2009) Anxiolytic effects of ayoga program in early breast cancer patients undergoing conven- tional treatment: a randomized controlled trial. Complement Ther Med 17(1): 1-8.

19. Bishop JL, Northstone K, Green JR, Thompson EA (2011) The use of Complementary and Alternative Medicine in pregnancy: data from the Avon Longitudinal Study of Parents and Children (ALSPAC). Complement Ther Med 19(6): 303-310.

20. Cohen L, Warneke C, Fouladi RT, Rodriguez MA, Chaoul-Reich A (2004) Psychological adjustment and sleep quality in a randomized trial of the effects of a Tibetan yoga intervention in patients with lymphoma. Cancer 100(10): 2253-2260.

21. Khalsa SB (2004) Treatment of chronic insomnia with yoga: a preliminary study with sleep-wake diaries. Appl Psychophysiol Biofeedback 29(4): 269-278.
22. Khalsa SBS A randomized controlled trial of a yoga treatment for chronic insomnia. Appl Psychophysiol Biofeedback. in press

23. Birdee GS, Yeh GY, Wayne PM, Phillips RS, Davis RB et al. (2009) Clinical applications of yoga for the pediatric population: a systematic review. Acad Pediatr 9(4): 212-220.

24. Galantino ML, Galbavy R, Quinn L (2008) Therapeutic effects of yoga for children: a systematic review of the literature. Pediatr Phys Ther 20(1): 66-80.

25. Kaley-Isley LC, Peterson J, Fischer C, Peterson E (2010) Yoga as a complementary therapy for children and adolescents: a guide for clinicians. Psychiatry (Edgmont) 7(8): 20-36.

26. Conboy LA, Noggle JJ, Frey JL, Kudesia RS, Khalsa SB (2013) Qualitative evaluation of a high school Yoga Program: Feasibility and perceived Benefits. Explore (NY) 9(3): 171-80.

27. Khalsa SB, Hickey-Schultz L, Cohen D, Steiner N, Cope S (2012) Evaluation of the mental health benefits of yoga in a secondary school: a preliminary randomized controlled trial. J Behav Health Serv Res 39(1): 80-89.

28. Lisa A Conboy, Jessica J Noggle, Jessica L Frey, Ravi S Kudesia, Sat Bir S Khalsa et at.al (2013) Qualitative evaluation of a high school Yoga Program: Feasibility and perceived Benefits Explore (NY) 9(3): 171-80.

29. Langøien LJ (2013) Pay Attention - Listen to Your Heart Unfolding Practice, Change Realities and Awareness of the Embodied Self in Ashtanga Yoga. Trondheim: Norwegian University of Science and Technology.

30. Balkrisna A (2010) Syllabus for Yoga. Concept of Yoga Education in India. Haridwar: Divya Prakashan.

31. Telles S (2012) The Effect of Yoga on Mental Health of Children. In Nayar U, editor Child and Adolescent Mental Health. New Dehli: Sage Publications 219-227.

32. Khalsa SBS (2013) Yoga in schools research: improving mental and emotional health. Invited Presentation at the Second International Conference on Yoga for Health and Social Transformation Haridwar: Patanjali Research Foundation.

33. Bhattacharya S, Pandey US, Verma NS (2002) Improvement in oxidative status with yogic breathing in young healthy males. Indian J Physiol Pharmacol 46(3): 349-354.

34. Martarelli D, Cocchioni M, Scuri S, Pompei P (2011) Diaphragmatic breathing reduces exercise-induced oxidative stress. Evid Based Complement Alternat Med.

35. Telles S, Nagarathna R, Nagendra HR, Desiraju T (1993) Physiological changes in sports teachers following 3 months of training in yoga. Indian J Med Sci 47(10): 235-238.

36. Conboy LA, Wilson A, Braun T (2010) Moving beyond health to flourishing: the effects of yoga teacher training. Scientific World Journal 10: 788-795.

37. Benavides S, Caballero J (2009) Ashtanga yoga for children and adolescents for weight management and psychological wellbeing: anuncontrolled open pilot study. Complement Ther Clin Pract 15(2): 110-114.

38. Douglass L (2011) Thinking through the body: the conceptualization of yoga as therapy for individuals with eating disorders. Eat Disord 19(1): 83-96.

39. Mehling WE, Wrubel J, Daubenmier JJ (2011) Body awareness: a phenomenological inquiry into the common ground of mind-body therapies. Philos Ethics Humanit Med 6-6. 
C. This work is licensed under Creative
Commons Attribution 4.0 License
DOI: $10.19080 / J Y P .2019 .07 .555720$

\section{Your next submission with Juniper Publishers will reach you the below assets}

- Quality Editorial service

- Swift Peer Review

- Reprints availability

- E-prints Service

- Manuscript Podcast for convenient understanding

- Global attainment for your research

- Manuscript accessibility in different formats

( Pdf, E-pub, Full Text, Audio)

- Unceasing customer service Track the below URL for one-step submission https://juniperpublishers.com/online-submission.php 